There will be enough only if there is a marked improvement in present conditions of pay and terms of service. The encouraging words in the report are no substitute.

The Government has backed the programme with $£ 40$ million additional capital and revenue resources over the period 1971-3. But even if growth continues for the next decade at the maximum rate envisaged by the Government there will be too few training places and homes for the mentally handicapped well into the 1980s. The report estimates that 36,800 residential places are needed for England and Wales; there are fewer than 5,000 at present. Adult day training centres should be able to cope with 72,500 patients; fewer than 25,000 places are available. Why are there so few places? The 1959 Mental Health Act laid a statutory duty on local authorities to provide a full range of community services for the mentally handicapped, including residential accommodation. Yet at the end of 1969 less than a quarter of the local authorities in England and Wales had provided homes of this kind for children and adults. Conditions for the mentally handicapped have improved in the last two or three years, and this new programme will lead to further improvements. But while the level of public interest and concern is low, and while some local authorities seem to "keep the rates down" by spending the minimum, there will still be parts of the country where little is done. Surely any national plan for better services should include some means of ensuring that the local authorities carry it out?

'Department of Health and Social Security. Better Services for the Mentally Handicapped, London, H.M.S.O., 1971. Price 45p.

\section{Non-bacterial Thrombotic Endocarditis}

Sterile vegetations are found on the heart valves in rheumatic carditis and rarely in systemic lupus erythematosus. They consist of platelets and fibrin and are deposited on the surface of an acutely inflamed valve. But sterile vegetations are sometimes also found on valves that are not grossly diseased. This condition is called non-bacterial thrombotic endocarditis, and it affects the mitral and aortic valves predominantly. At the most the changes are confined to a slight degeneration of the collagen framework of the valve. ${ }^{1}$

Non-bacterial thrombotic endocarditis was for long dismissed as a terminal phenomenon of little clinical importance. But in a series of 78 cases R. A. Macdonald and S. L. Robbins found 11 instances of systemic embolism arising from the affected valve, and this either caused or contributed to the patient's death. ${ }^{2}$ Furthermore, these embolic episodes were sometimes the first indication of a systemic illness, and the endocarditis could not be regarded as a terminal event. Over a third of the patients had widespread cancer, and in most of the remainder death was due to heart failure or vascular thrombotic disease.

There seems to be an association between non-bacterial thrombotic endocarditis and cancer. ${ }^{34}$ Thus W. E. Barry and D. Scarpelli found metastatic carcinoma in 12 of their 21 cases, while two others died of leukaemia. ${ }^{5}$ Of the 16 cases collected by R. F. Rohner and his colleagues ten had disseminated cancer, and of these, seven were mucussecreting adenocarcinomata of the stomach, lung, colon, and pancreas. These mucoid cancers were associated with multi- ple large vegetations. ${ }^{6} \mathrm{M}$. RayChaudhuri has recently described four further cases occurring in association with mucus-secreting adenocarcinomata, two bronchial in origin and the others gastric and pancreatic. ${ }^{7}$ In all the cases there were multiple systemic infarcts and also widespread venous thrombosis. The mitral valves were alone affected, and the cusps showed mild degenerative changes in the collagen framework.

The aetiology of non-bacterial thrombotic endocarditis is obscure and its relation to disseminated cancer is not understood. It has been suggested that there is an increased tendency for the blood to clot owing to a possible alteration in the levels of various clotting factors or to the liberation of a mucin-like substance which accelerates the clotting mechanism, but no single finding has been substantiated. Migratory thrombophlebitis is often present as well, ${ }^{6}$ and this adds weight to the possibility that the blood is hypercoagulable. The condition is in fact an uncommon complication even of mucus-secreting adenocarcinomata, and RayChaudhuri found it in only four of a series of 232 cases. $^{7}$ Whatever the aetiology of non-bacterial thrombotic endocarditis, it is clearly of clinical importance and may lead to systemic embolism and infarction.

Eritish Medical fournal, 1967, 3, 812.

Macdonald, R. A., and Robbins, S. L., Annals of Internal Medicine, 1957, 46, 255.

${ }^{3}$ Smith, J. P., and Yates, P. O., fournal of Pathology and Bacteriology, 1955, 70, 111 .

' Lafier, C. J., and Hinerman, D. L., Cancer, (Philadelphia), 1961, 14, 944.

Barry, W. E., and Scarpelli, D., Archives of Internal Medicine, 1962, 109, 151.

Rohner, R. F., Prior, J. T., and Sipple, J. H., Cancer, (Philadelphia), $1966,19,1805$.

RayChaudhuri, M., British Fournal of Diseases of the Chest, 1971, 65, 98.

\section{Ward Design and Cross- infection}

Infection from patient to patient by staphylococci involves an ever-present threat of sepsis, particularly in surgical wards, and has been extensively studied in Great Britain for some time past. The effect of subdivision has naturally attracted most attention, and an extreme example of this, an infectious diseases ward consisting entirely of single rooms opening on a veranda, was found by $M$. T. Parker and his colleagues ${ }^{1}$ to approach the ideal. Very little exchange of staphylococci between patients occurred. This arrangement is almost impracticable in general hospital wards, and the tendency there has been towards subdivision of most of the accommodation into rooms containing four beds.

A somewhat belated report ${ }^{2}$ (this study was carried out in 1965-6) on conditions in such wards in the Queen Elizabeth II Hospital, Welwyn Garden City, has recently appeared. Here the four-bed rooms are separated from a corridor and thus from the rest of the ward only by a wall $3 \mathrm{ft} .(1 \mathrm{~m})$ high. The usual methods of air sampling and of weekly nasal swabbing of all patients and staff were employed, together with phage typing and antibiotic sensitivity determinations of all strains isolated. Advanced mathematical procedures and a computer were used to analyse the results. Not only did nasal colonization, including that by antibioticresistant strains, increase for five weeks after admission, but evidence was obtained that the source was almost as likely to 